Document downloaded from:

http://hdl.handle.net/10251/151305

This paper must be cited as:

Wegrzyn, M.; Galindo-Galiana, B.; Benedito, A.; Giménez Torres, E. (2015). Morphology, thermal, and electrical properties of polypropylene hybrid composites co-filled with multiwalled carbon nanotubes and graphene nanoplatelets. Journal of Applied Polymer Science. 132(46). https://doi.org/10.1002/app.42793

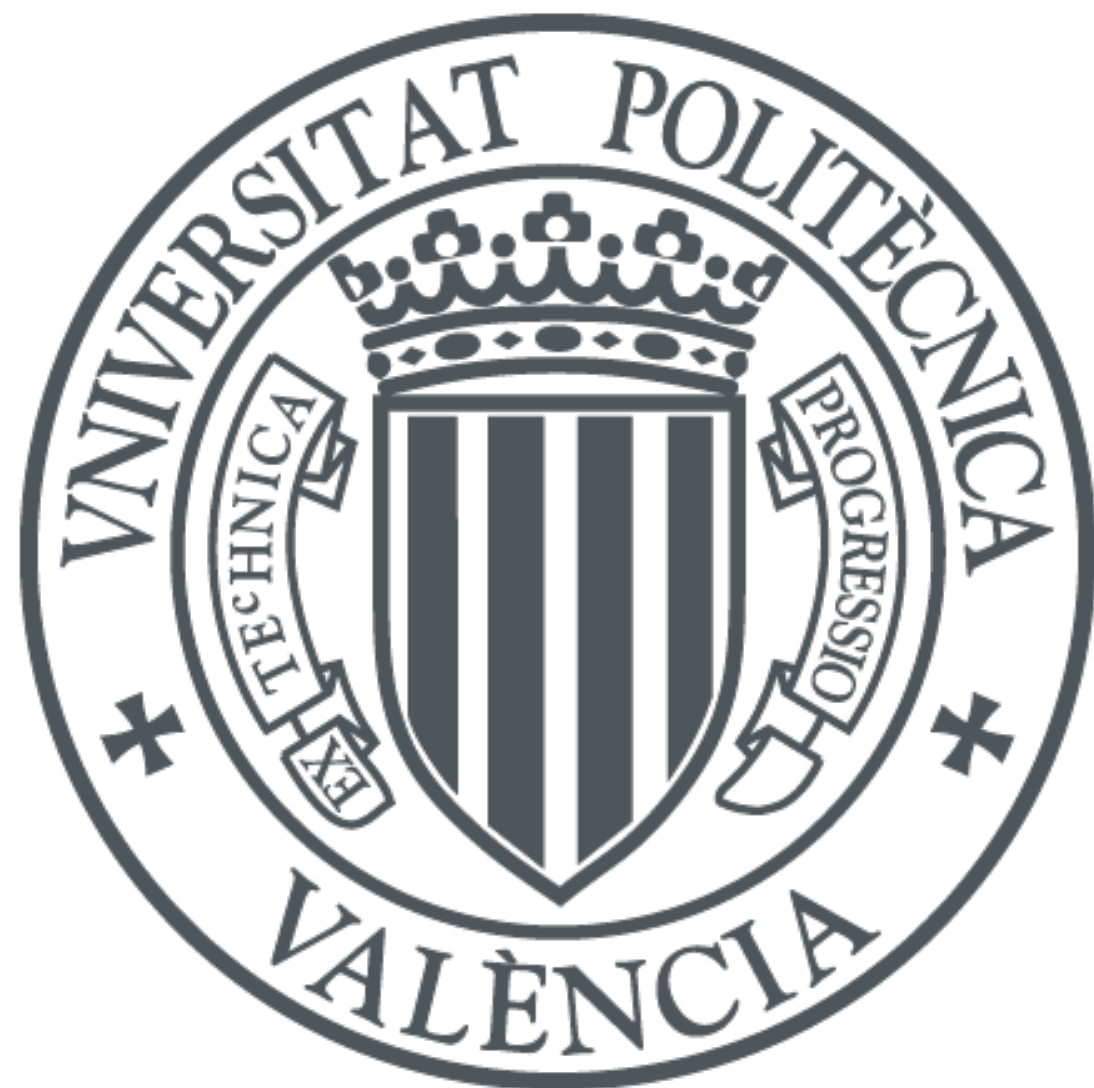

The final publication is available at

https://doi.org/10.1002/app.42793

Copyright John Wiley \& Sons

Additional Information

"This is the peer reviewed version of the following article:

Wegrzyn, M., Galindo, B., Benedito, A., \& Gimenez, E. (2015). Morphology, thermal, and electrical properties of polypropylene hybrid composites co\&\#8208;filled with multi\&\#208;walled carbon nanotubes and graphene nanoplatelets. Journal of Applied Polymer Science, 132(46)., which has been published in final form at https://doi.org/10.1002/app.42793. This article may be used for non-commercial purposes in 


\title{
Morphology, thermal and electrical properties of polypropylene hybrid composites co-filled with multi-walled carbon nanotubes and graphene nanoplatelets.
}

\author{
Marcin Wegrzyn ${ }^{a *}$, Begoña Galindo ${ }^{a}$, Adolfo Benedito $^{a}$, Enrique Gimenez ${ }^{b}$ \\ a Instituto Tecnológico del Plástico (AIMPLAS), Calle Gustave Eiffel 4, 46980 Paterna, Spain \\ ${ }^{b}$ Instituto de Tecnología de Materiales. Universidad Politécnica de Valencia, Camino de Vera, 46022 \\ Valencia, Spain
}

Correspondence: e-mail: marcinwegrzyn@hotmail.com

\section{ABSTRACT}

In this work, nanocomposites of polypropylene (PP) with various loads of multi-wall carbon nanotubes (MWCNT) and graphene nanoplatelets (GnP) were formed by a masterbatch dilution approach from individual masterbatches PP-MWCNT and PP-GnP. Melt mixing on a twin-screw extruder at two different processing temperatures was followed by characterization of morphology by transmitted-light microscopy including the statistical analysis of agglomeration behavior. The influence of both nanofillers weight fraction on the dispersion quality is reported. Thermal properties investigated by DSC and TGA also show the sensitivity to nanofillers weight fraction ratio and processing conditions. Electrical conductivity increases up to an order of magnitude when the concentration of each nanofiller increases from $0.5 \mathrm{wt} . \%$ to $1.0 \mathrm{wt} . \%$. This is co-related with a decrease of electrical conductivity observed for unequal concentration of both nanofillers. However, this particular behavior shows the increase of electrical properties for higher MWCNT load and the increase of thermo-mechanical properties for higher GnP load.

\section{KEYWORDS}

Hybrid Composite; Carbon Nanotube; Graphene Nanoplatelets. 


\section{INTRODUCTION}

Carbon nanotubes have gained attention of material science community confirming the ability to boost electrical and thermal properties of insulating polymers. [1,2] Uncommon properties of this material being a result of a unique structure and a high aspect ratio enable an improvement of mechanical properties of polymer matrices. [3,4] However, carbon nanotubes often described as one-dimensional structures are recently confronted with the two-dimensional graphene, when polymer filling is in consideration. [5] Even though the aim of formation the graphene oxide-based nanocomposites is usually an increase of mechanical properties, [6] a significant influence on electrical and thermal properties has been reported in these materials. [7] The main issue that distracts the desired improvement of polymers is reported for both nanomaterials difficulty in achieving homogeneous dispersions in thermoplastic matrix. $[8,9]$ The agglomeration behavior of individual nanoparticles is driven by the attractive Van der Waals forces between the individual nanoparticles and can be reduced in extrusion process by the proper selection of processing conditions. [10] This is related with a breakage of primary carbon nanotube agglomerates in the process of macrostructure penetration by polymer melt [10] or by the exfoliation of graphite in order to obtain monolayer sheets of graphene nanoplatelets. [11] Usually proper processing parameters including high screw speed and low barrel temperature provide homogeneous morphologies. However, these conditions must be included in a factor specific mechanical energy (SME) that defines the energy applied to the nanocomposite melt during melt-mixing. [12] The mutual relation between the viscosity of thermoplastic melt, screw speed and temperature profile applied during processing is a complex phenomenon. Thus, the use of SME is usually suggested in order to have a proper control over the entire nanocomposite system.

The examples of melt-mixed nanocomposites with matrices of commodity polymers exist in the literature with carbon-based fillers, carbon nanotubes or graphene nanoplatelets: polyethylene (PE), $[13,14]$ polypropylene (PP) $[15,16]$ and polystyrene (PS). $[17,18]$ Nevertheless, polymer-based nanocomposites co-filled with these nanofillers in order to form a hybrid system are studied mainly with scientific approach. $[19,20]$ Reports show the tendency of quite common use of thermoset matrix for such study of complex filler systems. [21,22] Basing of these works, the synergistic effect and carbon nanotubes-to-graphene nanoplatelets ratio are shown to influence the key final properties, e.g. 
tensile strength. Furthermore, alignment of carbon nanotubes or graphene flakes caused by the shear during processing causes the formation of an interconnected network in the matrix [21] giving a significant improvement of thermal conductivity. [22] In order to obtain better dispersions of nanophase and boost the final properties, the additives like wax [23] or surfactants [24] are commonly used in the preparation process of co-filled nanocomposites with thermoplastic matrix. Thus, an increase of electrical and mechanical properties in thermoplastic nanocomposites co-filled with MWCNT and GnP is correlated with the morphology. This is observed for both: semi-crystalline $[23,25]$ and amorphous [24] matrices. Besides that, semi-crystalline polymers show an increase of crystallinity after carbon nanotubes or graphene nanoplatelets incorporation, which is explained by the nucleation effects [25].

In this work, we present PP-MWCNT/GnP nanocomposites prepared with scalable industrial approach by mixing and dilution of pre-dispersed masterbatches on twin-screw extruder at two processing temperatures. Such attempts of nanocomposites preparation are usually omitted in the field of co-filled thermoplastics research. Various total nanofillers content and control of nanofillers ratio allows studying the influence of synergistic effect. The effects of specific mechanical energy (SME) applied to the material during processing shows the influence of used temperature profiles. Morphology of the nanocomposites is characterized by the light-transmission microscopy (LTM) and agglomeration behavior is determined by statistical methods. Thermal properties investigated by thermo-gravimetric analyses (TGA) and differential scanning calorimetry (DSC) along with thermo-mechanical properties studied by dynamic-mechanical analysis (DMA) show relationship with the morphology.

\section{EXPERIMENTAL}

\section{- Materials}

Commercial polypropylene (PP) Domolen 1101S (MFR $24 \mathrm{~g} / 10 \mathrm{~min}$ ) was supplied by DOMO Chemicals. Multi-walled carbon nanotubes (MWCNT) NC7000 with average diameter $9.5 \mathrm{~nm}$ and average length $1.5 \mu \mathrm{m}$ were supplied by Nanocyl. Graphene nanoplatelets (GnP) XGnP-M5 with thickness 5-8 $\mathrm{nm}$ were supplied by XG Sciences. 


\section{- Preparation of nanocomposites}

Nanocomposites with various nanofillers concentration (Table 1) were prepared with masterbatch mixing/dilution approach. Masterbatches of polypropylene/multi-walled carbon nanotubes (PPMWCNT) and polypropylene/graphene nanoplatelets (PP-GnP) (each containing 15 wt. \% nanofiller) were prepared by melt-mixing on a Coperion ZSK 25 co-rotating twin-screw extruder with a screw speed $400 \mathrm{rpm}$ and a throughput $6 \mathrm{kgh}^{-1}$. The final nanocomposites were subsequently formed by mixing the PP-MWCNT and the PP-GnP masterbatches with neat polypropylene at various ratios to concentrations present in Table 1. The formation of final nanocomposites was carried out on a Prism Eurolab 16 (Thermo Fisher Scientific) co-rotating twin-screw extruder (L/D 25). Nanocomposites were produced at two screw temperature profiles: $170-200^{\circ} \mathrm{C}$ (low temperature profile) or $190-240^{\circ} \mathrm{C}$ (high temperature profile) with a screw speed of $600 \mathrm{rpm}$.

Rectangular samples with dimensions of $60 \times 10 \times 2 \mathrm{~mm}^{3}$ (following the modified standard ISO 127) were compression molded on a Collin 6300 hydraulic press with a 20 minutes five-step program at 190 ${ }^{\circ} \mathrm{C}$ in order to be used in electrical conductivity measurements.

\section{- Characterization}

Morphology of the nanocomposites was studied by transmitted-light microscopy (LTM) on a Leica DMRX microscope Films 20-50 $\mu \mathrm{m}$ thick for LTM study were hot-pressed from pellets. Agglomeration behavior was carried out on Leica Materials Workstation software. Agglomeration density was evaluated as a ratio of agglomerated area to the total investigated area of measured discs.

Thermo-gravimetric analysis (TGA) was done on a Q5000 instrument (TA Instruments). Pellets weighting $10 \mathrm{mg}$ were heated from $50^{\circ} \mathrm{C}$ to $800^{\circ} \mathrm{C}$ at a heating rate of $20^{\circ} \mathrm{Cmin}^{-1}$ in a nitrogen atmosphere. Differential scanning calorimetry (DSC) was done on a Diamond (Perkin-Elmer). Each sample was heated from $40^{\circ} \mathrm{C}$ to $240^{\circ} \mathrm{C}$ at a heating rate of $10^{\circ} \mathrm{Cmin}^{-1}$ to erase the thermal history. This was followed by cooling to $40^{\circ} \mathrm{C}$ at the same rate and then by a second heating to $240{ }^{\circ} \mathrm{C}$ in order to determine the melting points and enthalpies. 
Electrical resistivity was measured by two-point contact configuration (following the ISO 3915 standard) on a Keithley 2000 Multimeter source/meter. Silver electrodes were painted on the samples in order to improve contact with the measuring electrodes.

\section{RESULTS AND DISCUSSION}

Macro-scale morphology of nanocomposites obtained by dilution of a pellets mixture containing PPMWCNT and PP-GnP with the virgin PP is shown on the LTM images in Figure 1 and Figure 2. The nanofillers dispersion level achieved for the studied MWCNT-GnP contents and for both temperature profiles applied during the dilution step varies. The study of these differences is divided between the fillers weight fraction ratio equal 1.0 (representing the same share of both fillers in the nanocomposite, shown in Figure 1) and fillers weight fraction ratio unequal 1.0 (representing different shares of each filler in the total load, shown in Figure 2). Thus, an increase of agglomeration behavior is observed for higher nanofillers load at both processing conditions shown in Figure 1. Furthermore, a clearly higher number of agglomerates is observed at high temperature profile for both compositions: $0.5 \mathrm{~T} / 0.5 \mathrm{P}$ (Figure 1c) and 1.0T/1.0P (Figure 1d). This effect can be explained by an expected decrease of matrix viscosity at higher processing temperatures, causing a reduction of force necessary for agglomerates breakage.

However, an uneven fillers weight fraction brings a deviation from this observation decreasing the nanocomposites sensitivity to processing conditions. No significant changes in agglomeration behavior are observed between 0.5T/1.0P processed at low temperature profile (Figure 2a) and at high temperature profile (Figure 2c). Analogous observation can be made for an opposite ratio of nanofillers load: 1.0T/0.5P (Figure 2b and Figure 2d). Nevertheless, a clear decrease of agglomerates number occurs when a nanocomposite contains higher load of multi-walled carbon nanotubes than graphene nanoplatelets. Such a change of morphology at similar total loads of nanofillers is observed for both applied processing conditions. This can be explained by various MWCNT and GnP dispersion abilities in PP matrix. Besides, graphene is known for its lubricating properties, which can cause an unwanted effect of the reduction of exfoliation/agglomerate breakage efficiency. [26] The presence of graphene may reduce interlaminar binding and cause slipping, which significantly reduces the final dispersion quality. On the other hand, carbon nanotubes are known to give uniform nanocomposites in different 
polymer matrices, which explain more homogeneous morphology of 1.0T/0.5P (e.g. Figure 2a) than 0.5T/1.OP (e.g. Figure 2b). Nevertheless, nanofiller dispersions in a mono-filled MWCNT-based nanocomposites are not subjected to the negative aforementioned influence of lubricant. Thus, theoretically these nanocomposites should give more homogeneous morphologies that the co-filled materials studied in this work.

Agglomeration behavior directly influencing the final morphology of PP-MWCNT/GnP nanocomposites is related with the specific mechanical energy (SME). Curves shown in the graph in Figure 3 are calculated with Equation (1), which includes $\varepsilon P$ representing effective power of the motor, $\tau$ representing torque and $v_{\text {proc }} / v_{\max }$ - screw speeds ratio. The throughput $Q$ was constant in the studied experiments. However, the influence of this parameter is reported in the literature [12].

$S M E=\frac{\varepsilon P \cdot \tau \cdot \frac{v_{\text {proc }}}{v_{\max }}}{Q}$

Therefore, the SME values for different nanofillers weight fractions shows how effective the processing conditions are for a specific composition. The energy applied to the material during the masterbatches dilution step varies significantly between applied temperature profiles. Lower processing temperature provides higher energy due to a higher viscosity of the melt. This is confirmed by the morphological study, where nanocomposites of the same compositions give better dispersions at low temperature profile (Figure 1a and Figure 1c). Besides that, an expected increase of SME is observed between $0.5 \mathrm{~T} / 0.5 \mathrm{P}$ and $1.0 \mathrm{~T} / 1.0 \mathrm{P}$ that is also related with increase of melt viscosity coming from the nanomaterials network formation in the polymer melt. Furthermore, the higher values of specific mechanical energy are observed for the compositions with higher carbon nanotube concentration (1.0T/0.5P), which is also related with the formation of continuous, interconnected network in polymer melt affecting the rheology of the whole system. The one-dimensional structures (MWCNT) are capable of forming such networks at significantly lower weight fractions than the flake-like structures $(\mathrm{GnP})$ and this is the explanation why the hybrid nanofillers system with higher carbon nanotubes load give higher torque readings than the analogous system with the increased graphene nanoplatelets concentration. The aforementioned difference between morphology of 1.0T/0.5G (Figure 2d) and 
0.5T/1.0P (Figure 2c), showing higher homogeneity of the former nanocomposite, confirms the observations of SME behavior.

The quality of nanocomposites morphology is additionally studied with the statistical methods based on agglomeration behavior investigated on LTM images. Table 2 and Table 3 contain parameters the description of the agglomeration behavior of PP-MWCNT/GnP nanocomposites. Agglomerate length and agglomerate area (Table 2) for the nanocomposites with fillers concentration ratio 1:1 (0.5T/0.5P and 1.0T/1.0P) show similar increase pattern with the nanofiller weight fraction for both studied temperature profiles. Such an effect is already described in the discussion of transmitted-light microscopy test (Figure 1). The influence of processing showing the decreasing agglomeration behavior when the low temperature profile is applied also agrees with the previous findings of the improved morphology for materials formed at such conditions. Besides that, the higher average values of agglomerate area and agglomerate length for 0.5T/1.0P than for 1.0T/0.5P correspond with the LTM images showing more homogeneous morphology for the latter nanocomposites (Figure 2). However, Figure 4 presenting the aspect ratio of individual agglomerates at applied conditions shows the trend opposite to the one observed in Table 1. Analysis of this parameter suggests that the agglomerate shape is more spherical at elevated nanofiller loads, at high processing temperature and when the sample contains higher content of GnP than MWCNT. All mentioned factors show also the negative effect on morphology. Thus the agglomerate aspect ratio should be directly related to the shear forces occurring in a twin-screw extruder and to the viscosity of the nanocomposite melt. Furthermore, the presence of co-nanofiller most probably distracts the whole system. Thus, the morphology of nanocomposite that is theoretically possible when each of the used nanofillers is individually dispersed in polypropylene will show worse performance for the hybrid-filler system.

A parameter shown in Table 3 represents the agglomerate size distribution and is defined as the agglomerate size that is larger from the $95 \%$ of all agglomerates observed in the specimen. An expected increase of this value for the increase of MWNCT/GnP content from $0.5 T / 0.5 \mathrm{P}$ to $1.0 \mathrm{~T} / 1.0 \mathrm{P}$ is observed. Besides that, the aforementioned in Figure 1 pattern of higher agglomeration presence in nanocomposites processed at high temperature profile agrees with the data in Table 3. Regarding the $95 \%$ population parameter for materials with uneven concentrations of MWCNT and GnP, the 0.5T/1.0P with characteristic poor morphology (when compared to the corresponding 1.0T/0.5P) 
shows high values. This is understood as a wider agglomerate size distribution and can be noticed in LTM images in Figure 2a.

Thermal properties of PP nanocomposites co-filled with carbon nanotubes and graphene nanoplatelets were studied on data collected during the DSC experiment. Table 4 shows the linear decrease of melting point onset and melting enthalpy $(\Delta \mathrm{H})$ with a gradual increase of nanofillers weight fraction. Similar behavior of melting temperature observed on other thermoplastic nanocomposites with the plate-like particles is reported to indicate a reduced degree of crystallinity at higher contents. [27] Besides, the well-dispersed nanofiller forming a network in the matrix usually cause an increase of transition temperatures. [28] Reduced confinement of polymer chains in the presence of agglomerated MWCNT and GnP restricts the formation of perfect crystals. Therefore, a high nanofillers content of 1.0T/1.0P and the presence of agglomerates distract the crystallites quality affecting the phase transition. This gives a significant reduction of melting temperature up to $3.8 \%$. Furthermore, nanocomposites with uneven concentration of fillers give the reduced values of both investigated parameters for $0.5 \mathrm{~T} / 1.0 \mathrm{P}$. This agrees with the LTM observations of better morphology for the material with higher content of carbon nanotubes (Figure $2 b$ ).

The representative results of thermo-gravimetric analysis present in Figure 5 include a half-mass loss temperature $\left(T_{50 \%}\right)$ observed during the thermal degradation experiment. A clear increase of matrix thermal stability for PP-MWCNT and PP-GnP nanocomposites is observed. The effect is stronger when carbon nanotubes are used as filler most probably due to the better dispersion achieved at the same processing conditions. Theoretically, these results should show a 2D material to give better results due to the better barrier properties distracting the undisturbed combustion gases emission from the specimen bulk. Nevertheless, the well-dispersed carbon nanotubes form a uniform network in the matrix showing the aforementioned barrier properties at sufficient level. Besides, the formation of char on the surface of the specimen during the decomposition shows similar barrier effect. Such structure may be tighter when the nanomaterial forming it is better distributed. Besides that, there is no synergy for the co-filled nanocomposites and a reduction of thermal stability for all PP-MWCNT/GnP materials is observed. This is most probably related with the non-sufficient homogeneity of the nanofillers and the effect of morphology decrease with the formation of a hybrid system. A slight increase of $T_{50 \%}$ with the increase of the total nanofiller load is observed to be stronger when a high temperature profile is 
used. This suggests a major importance of the nanofiller content over the dispersion quality in thermal stability of hybrid filler system-based nanocomposites.

Thermo-mechanical properties of PP-MWCNT/GnP nanocomposites, slightly lower at low-temperature profile, are shown in Figure 6. The curves of storage modulus change with the temperature do not increase linearly with the total nanofiller load. Instead of that, the increase of storage modulus is generally observed with the increase of $\mathrm{GnP}$ weight fraction share in the total nanofiller load (increase of the ratio graphene nanoplatelets-to-carbon nanotubes load). Only material with the lowest load $(0.5 \mathrm{~T} / 0.5 \mathrm{G})$ does not agree with this pattern, which can be explained with the insufficient total load. The main effect is partially related with the total load of nanofillers in polypropylene, but the composition of the co-nanofillers also seems to play an important role, which is explained by morphology and synergy effect. This can be observed by the higher value of storage modulus for 0.5T/1.0G (total nanofillers load 1.5 wt. \%) than for 1.0T/1.0G (total load 2.0 wt. \%). Explanation of the uncommon pattern in storage modulus dependence on nanofiller load is related to the character of nanoparticles. Graphene nanoplatelets are reported to improve mechanical properties better than carbon nanotubes due to their geometry. [21] Thus, the processing conditions seem to have comparable significance in controlling the effect of carbon-based nanofillers on thermo-mechanical properties than the load.

Table 6 presents the electrical conductivity values measured by a two-point method described elsewhere. [29] For the nanocomposites wit fillers ratio 1:1, a 190-200 \% increase of electrical conductivity is achieved with an increase of nanofiller content from $0.5 \mathrm{wt} . \%(0.5 \mathrm{~T} / 0.5 \mathrm{P})$ to $1.0 \mathrm{wt} . \%$ (1.0T/1.0P). Such an improvement of electrical properties can be correlated with the presence of two different geometry nanofillers and with the possible presence of interconnected network of carbon nanotubes and graphene nanoplatelets. Nevertheless, a significant reduction of electrical conductivity is observed when the 1:1 ratio between nanofiller content is disturbed. This can be caused by a statistical need of the presence of both fillers in order to provide efficient MWCNT-GnP bridging. However, it seems that mainly one-dimensional carbon nanotubes are responsible for the electrical charge paths formation inside the matrix, which is confirmed by a c.a. $55 \%$ higher electrical conductivity of $1.0 \mathrm{~T} / 0.5 \mathrm{P}$ than $0.5 \mathrm{~T} / 1.0 \mathrm{P}$. The presence of a good distribution and interconnection of agglomerates rather than a perfect carbon nanotube network is needed for high electrical conductivity. [30] On the contrary, the greater improvement of electrical properties present in materials melt-mixed 
at higher temperature does not seem to show strong correlation with homogeneous nanofillers dispersion, which is achieved at low temperature profile (Figure 1). Thus, a high processing temperature most probably induces changes in matrix-nanofiller interactions causing an increase of conductivity. Similar effect of processing temperature was reported in thermoplastic nanocomposites. $[31,32]$

\section{CONCLUSIONS}

In this work we present industrially accepted approach for preparation of polypropylene nanocomposites co-filled with carbon nanotubes and graphene nanoplatelets. Masterbatches dilution/mixing approach carried out on a twin-screw extruder at two different temperature profiles shows differences in morphology of the final nanocomposites. A clear reduction of agglomeration is observed in transmitted-light microscopy images when the nanocomposite contains higher load of carbon nanotubes than graphene nanoplatelets. This effect is correlated with the specific mechanical energy and confirmed by a statistical study of agglomeration behavior. Furthermore, a decrease of agglomeration behavior is observed at lower applied processing temperature. A reduction of the nanocomposites melting temperature, greater for uneven nanofillers content, is explained by a distraction of matrix crystallization caused by agglomeration. Similar behavior for uneven nanofillers content is observed for electrical conductivity showing the greater decrease of values when the graphene nanoplatelets load is higher than carbon nanotubes load. On the contrary, the thermomechanical properties are improved for higher graphene content.

Electron microscopy study of nano-scale morphology in the PP-MWCNT/GnP nanocomposites needs to be performed. Besides, a more complete study of electrical conductivity in co-filled polypropylene need to be carried out in order to provide more precise data regarding the influence of processing conditions and reveal the characteristic parameters of each nanocomposite material, e.g. electrical percolation threshold.

\section{ACKNOWLEDGEMENTS}


This work is funded by the European Community's Seventh Framework Program (FP7-PEOPLE-ITN2008) within the CONTACT project Marie Curie Fellowship under grant number 238363.

\section{REFERENCES}

[1] L. Yang, F. Liu, H. Xia, X. Qian, K. Shen, J. Zhang; Improving the electrical conductivity of a carbon nanotube/polypropylene composite by vibration during injection moulding; Carbon, 2011, 49, 32743283.

[2] I.V. Singh, M. Tanaka, M. Endo; Effect of interface on the thermal conductivity of carbon nanotube composites; Int. J. Therm. Sci., 2007, 46, 842-847.

[3] H.-C. Kuan, C.-C.M. Ma, W.-P. Chang, S.-M. Yuen, H.-H. Wu, T.-M. Lee; Synthesis, thermal, mechanical and rheological properties of multiwall carbon nanotube/waterborne polyurethane nanocomposite; Comp. Sci. Tech., 2005, 65, 1703-1710.

[4] R. Arasteh, M. Omidi, A.H.A. Rousta, H. Kazerooni; A Study on Effect of Waviness of Mechanical Properties of Multi-Walled Carbon Nanotube/Epoxy Composites Using Halpin-Tsai Theory; J. Macromol. Sci. B, 2011, 50, 2464-2480.

[5] M. Martin-Gallego, R. Verdejo, M. Khayet, J.M. Ortiz de Zarate, M. Essalhi, M.A. Lopez-Manchado; Thermal conductivity of carbon nanotubes and graphene in epoxy nanofluids and nanocomposites; Nanoscale Res. Lett., 2011, 610, 1-7.

[6] D. Cai, J. Jin, K. Yusoh, R. Rafiq, M. Song; High performance polyurethane/functionalized graphene nanocomposites with improved mechanical and thermal properties; Compos. Sci. Technol., 2012, 72, 702-707.

[7] D. Yan, H.-B. Zhang, Y. Jia, J. Hu, X.-Y. Qi, Z. Zhang Z-.Z. Yu; Improved Electrical Conductivity of Polyamide 12/Graphene Nanocomposites with Maleated Polyethylene-Octene Rubber Prepared by Melt Compounding; ACS Appl. Mater. Inter., 2012, 4, 4740-4742.

[8] M.D. Haslam, B. Raeymaekers; A composite index to quantify dispersion of carbon nanotubes in polymer-based composite materials; Comp. B, 2013, 55, 16-21. 
[9] T. Kuilla, S. Bhadra, D. Yao, N.H. Kim, S. Bose, J.H. Lee; Recent advances in graphene based polymer composites; Prog. Polym. Sci., 2010, 35, 1350-1375.

[10] P. Pötschke, S.M. Dudkin, I. Alig; Dielectric spectroscopy on melt processed polycarbonate multiwalled carbon nanotube composites; Polymer, 2003, 44, 5023-5030.

[11] S. Stankovich, D.A. Dikin, G.H. Dommett, K.M. Kohlhaas, E.J. Zimney, E.A. Stach, R.D. Piner, S.T. Nguyen, R.S. Ruoff, Graphene-based composite materials, Nature, 2006, 442, 282-286.

[12] S. Sathyanarayana, G. Olowojoba, P. Weiss, B. Calgar, B. Pataki, I. Mikonsaari, C. Huebner, F. Hening; Compounding of MWCNTs with PS in a Twin-Screw Extruder with Varying Process Parameters: Morphology, Interfacial Behavior, Thermal Stability, Rheology, and Volume Resistivity; Macromol. Mater. Eng., 2013, 298, 89-105.

[13] J.F. Vega, J. Martinez-Salazar, M. Trujillo, M.L. Arnal, A.J. Müller, S. Bredeau, Ph. Dubois; Rheology, processing, tensile properties, and crystallization of polyethylene/carbon nanotube nanocomposites; Macromolecules, 2009, 42, 4719-4727.

[14] H. Kim, S. Kobayashi, M.A. AbdurRahim, M.J. Zhang, A. Khusainova, M.A. Hillmyer, A.A. Abdala, C.W. Macosko; Graphene/polyethylene nanocomposites: Effect of polyethylene functionalization and blending methods; Polymer, 2011, 52, 1837-1846.

[15] I. Alig, D. Lellinger, S. Dudkin, P. Pötschke; Conductivity spectroscopy on melt processed polypropylene-multiwalled carbon nanotube composites: Recovery after shear and crystallization; Polymer, 2007, 49, 1020-1029.

[16] M. Chaharmahali, Y. Hamzeh, G. Ebrahimi, A. Ashori, I.Ghasemi; Effects of nano-graphene on the physic-mechanical properties of bagasse/polypropylene composites; Polym. Bull., 2014, 71, 337349.

[17] D.E. Hill, Y. Lin, A.M. Rao, L.F. Allard, Y.P. Sun; Functionalization of carbon nanotubes with polystyrene; Macromolecules, 2002, 35, 9466-9471.

[18] Y.-H. Yu, Y.-Y. Lin, C.-H. Lin, C.-C. Chan, Y.-C. Huang; High-performance polystyrene/graphenebased nanocomposites with excellent anti-corrosion properties; Polym. Chem.,2014, 5, 535-550. 
[19] S. Zhang, S. Yin, C. Rong, P. Huo, Z. Jiang, G. Wang; Synergistic effects of functionalized graphene and functionalized multi-walled carbon nanotubes on the electrical and mechanical properties of poly(ether sulfone) composites; Eur. Polym. J., 2013, 49, 3125-3134.

[20] G. Huang, S. Wang, P. Song, C. Wu, S. Chen, X. Wang; Combination effect of carbon nanotubes with graphene on intumescent flame-retardant polypropylene nanocomposites; Comp. $A, \mathbf{2 0 1 4}, 59$, 1825.

[21] S. Chatterjee, F. Nafezarefi, N.H. Tai, L. Schlagenhauf, F.A. Nüesch, B.T.T. Chu; Size and synergy effects of nanofiller hybrids including graphene nanoplatelets and carbon nanotubes in mechanical properties of epoxy composites; Carbon, 2012, 50, 5380-5386.

[22] H. Im, J. Kim; Thermal conductivity of a graphene oxide-carbon nanotube hybrid/epoxy composite; Carbon, 2012, 50, 5429-5440.

[23] X. Jiang, L.T. Drzal; Improving electrical conductivity and mechanical properties of high density polyethylene through incorporation of paraffin wax coated exfoliated graphene nanoplatelets and multi-wall carbon nano-tubes; Comp. A, 2011, 42, 1840-1849.

[24] S.-H. Hwang, H.W. Park, Y.-B. Park, M.-K. Um, J.-H. Byun, S. Kwon; Electromechanical strain sensing using polycarbonate-impregnated carbon nanotube-graphene naoplatelet hybrid composite sheets; Comp. Sci. Tech., 2013, 89, 1-9.

[25] S. Chatterjee, F.A. Nüesch, B.T.T. Chu; Crystalline and tensile properties of carbon nanotube and graphene reinforced polyamide 12 fibers; Chem. Phys. Lett., 2013, 557, 92-96.

[26] D. Lahiri, F. Hec, M. Thiesse, A. Durygin, C. Zhang, A. Agarwal; Nanotribilogical behavior of graphene nanoplatelet reinforced ultra high molecular weight polyethylene composites; Tribol. Int., 2014, 70, 165-169.

[27] S. Pavlidou, C.D. Papaspyrides; A review on polymer-layered silicate nanocomposites; Prog. Polym. Sci., 2008, 33, 1119-1198.

[28] S.P. Su, Y.H. Xu, C.A. Wilkie; Thermal degradation of polymer-carbon nanotube composites; Polymer-carbon nanotube composites: Preparation, properties and applications; Editors: T. McNally, P. Pötschke; ISBN 1-84569-761-8; Woodhead Publishing, 2011, Chapter 16. 
[29] M. Wegrzyn, S. Juan, A. Benedito, E. Gimenez; The influence of injection molding parameters on electrical properties of PC/ABS-MWCNT nanocomposites; J. Appl. Polym. Sci., 2013, 130, 2152-2158.

[30] S.Pegel, T. Villmow, P. Pötschke; Quantification of dispersion and distribution of carbon nanotubes in polymer composites using microscopy techniques; Polymer-carbon nanotube composites: Preparation, properties and applications; Editors: T. McNally, P. Pötschke; ISBN 1-84569761-8; Woodhead Publishing, 2011, Chapter 9.

[31] R. Zhang, K.-S. Moon, W. Lin, C.P. Wong; Preparation of highly conductive polymer nanocomposite by low temperature sintering of silver nanoparticles, J. Mater. Chem., 2010, 20, 20182023.

[32] N. Grossiord, P.J.J. Kivit, J. Loos, J. Meuldijk, A.V. Kytylyuk, P. van der Schoot, C.E. Koning; On the influence of the processing conditions on the performance of electrically conductive carbon nanotube/polymer nanocomposites; Polymer, 2008, 49, 2866-2872. 


\section{$\underline{\text { TABLES }}$}

Table 1: Nanofillers content in prepared nanocomposites and samples codification.

\begin{tabular}{lccc}
\hline Sample code & MWCNT content & GnP content & Total nanofiller content \\
\hline $\mathbf{0 . 5 T / 0 . 5 P}$ & 0.5 wt. \% & 0.5 wt. \% & $1.0 \mathrm{wt.} \%$ \\
$\mathbf{0 . 5 T / 1 . 0 P}$ & 0.5 wt. \% & $1.0 \mathrm{wt} \%$ & $1.5 \mathrm{wt} \%$ \\
$\mathbf{1 . 0 T / 0 . 5 P}$ & $1.0 \mathrm{wt} . \%$ & $0.5 \mathrm{wt} \%$ & $1.5 \mathrm{wt} \%$ \\
$\mathbf{1 . 0 T / 1 . 0 P}$ & $1.0 \mathrm{wt} \%$ & $1.0 \mathrm{wt} \%$ & $2.0 \mathrm{wt} \%$ \\
\hline
\end{tabular}

Table 2: Agglomerate length and agglomerate area in polypropylene nanocomposites filled with carbon nanotubes and graphene nanoplatelets.

\begin{tabular}{lcccc}
\hline & \multicolumn{2}{c}{ Agglomerate length $[\mu \mathrm{m}]$} & \multicolumn{2}{c}{ Agglomerate Area $\left[\mu \mathrm{m}^{2}\right]$} \\
& Low temp. profile & High temp. profile & Low temp. profile & High temp. profile \\
\hline $\mathbf{0 . 5 T / 0 . 5 P}$ & $9.794( \pm 0.17)$ & $10.210( \pm 0.09)$ & $55.628( \pm 2.06)$ & $61.163( \pm 1.51)$ \\
$\mathbf{0 . 5 T / 1 . 0 P}$ & $10.761( \pm 0.30)$ & $10.872( \pm 0.11)$ & $66.747( \pm 0.97)$ & $71.106( \pm 3.02)$ \\
1.0T/0.5P & $10.056( \pm 0.25)$ & $10.359( \pm 0.16)$ & $58.964( \pm 3.21)$ & $66.232( \pm 4.28)$ \\
1.0T/1.0P & $10.697( \pm 0.42)$ & $12.002( \pm 0.21)$ & $69.477( \pm 4.17)$ & $86.209( \pm 5.10)$ \\
\hline
\end{tabular}

Table 3: Agglomerates distribution in polypropylene nanocomposites filled with carbon nanotubes and graphene nanoplatelets.

\begin{tabular}{lcc}
\hline & \multicolumn{2}{c}{$95 \%$ population $[\mu \mathrm{m}]$} \\
& Low temp. profile & High temp. profile \\
\hline 0.5T/0.5P & $20.0( \pm 0.35)$ & $20.5( \pm 0.20)$ \\
0.5T/1.0P & $21.5( \pm 0.39)$ & $22.0( \pm 0.28)$ \\
1.0T/0.5P & $20.0( \pm 0.48)$ & $21.5( \pm 0.43)$ \\
1.0T/1.0P & $22.0( \pm 0.51)$ & $24.0( \pm 0.62)$ \\
\hline
\end{tabular}


Table 4: Melting temperature of polypropylene nanocomposites filled with carbon nanotubes and graphene nanoplatelets.

Peak onset $\left[{ }^{\circ} \mathrm{C}\right]$

Low temp. profile High temp. profile Low temp. profile High temp. profile

\begin{tabular}{ccccc}
\hline PP & $155.79( \pm 0.09)$ & $155.92( \pm 0.09)$ & $108.92( \pm 0.11)$ & $108.76( \pm 0.10)$ \\
$\mathbf{0 . 5 T / 0 . 5 P}$ & $153.42( \pm 0.75)$ & $153.59( \pm 0.83)$ & $106.85( \pm 0.36)$ & $107.64( \pm 0.34)$ \\
$\mathbf{0 . 5 T / 1 . 0 P}$ & $149.87( \pm 0.65)$ & $150.93( \pm 0.10)$ & $106.06( \pm 0.16)$ & $106.57( \pm 0.27)$ \\
$\mathbf{1 . 0 T / 0 . 5 P}$ & $150.98( \pm 0.64)$ & $152.02( \pm 0.46)$ & $106.39( \pm 0.14)$ & $107.43( \pm 0.18)$ \\
$\mathbf{1 . 0 T / 1 . 0 P}$ & $149.60( \pm 0.13)$ & $150.19( \pm 0.05)$ & $105.42( \pm 0.22)$ & $106.39( \pm 0.33)$ \\
\hline
\end{tabular}

Table 5: Electrical conductivity of polypropylene nanocomposites filled with carbon nanotubes and graphene nanoplatelets.

\begin{tabular}{lcc}
\hline & \multicolumn{2}{c}{ Electrical conductivity $\left[\mathrm{Scm}^{-1}\right]$} \\
& Low temp. profile & High temp. profile \\
\hline $\mathbf{0 . 5 T / 0 . 5 P}$ & $3.6910^{-4}\left( \pm 4.0610^{-5}\right)$ & $4.1110^{-4}\left( \pm 4.9410^{-5}\right)$ \\
$\mathbf{0 . 5 T / 1 . 0 P}$ & $3.7710^{-6}\left( \pm 3.9210^{-5}\right)$ & $8.3710^{-5}\left( \pm 4.3110^{-5}\right)$ \\
$\mathbf{1 . 0 T / 0 . 5 P}$ & $2.5510^{-5}\left( \pm 3.2110^{-5}\right)$ & $1.3710^{-4}\left( \pm 5.1410^{-5}\right)$ \\
$\mathbf{1 . 0 T / 1 . 0 P}$ & $7.1410^{-4}\left( \pm 5.8710^{-5}\right)$ & $1.2010^{-3}\left( \pm 6.0210^{-5}\right)$ \\
\hline
\end{tabular}




\section{$\underline{\text { FIGURES }}$}

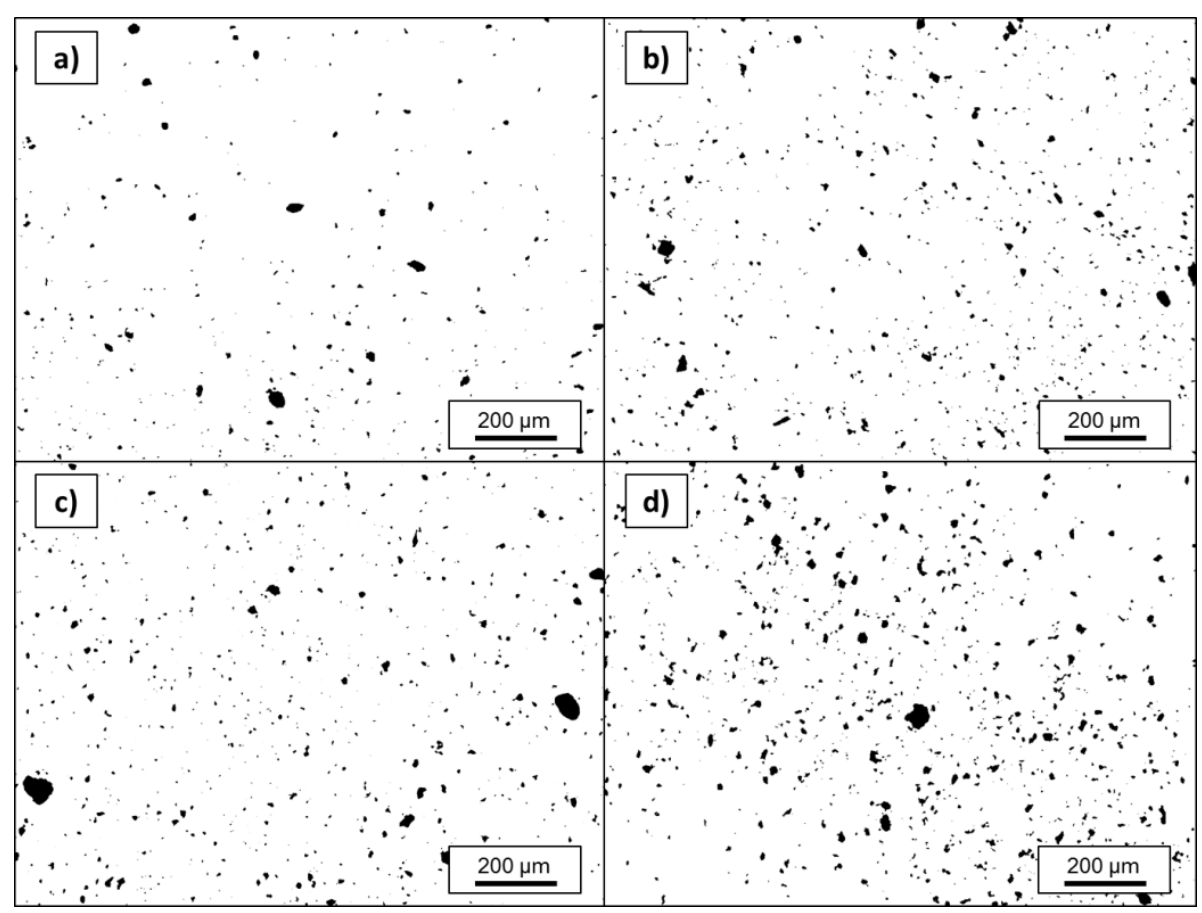

Figure 1: Light-transmission microscopy of polypropylene nanocomposites: a) 0.5T/0.5P Low temperature profile, b) 1.0T/1.0P Low temperature profile, c) 0.5T/0.5P High temperature profile, d) 1.0T/1.0P High temperature profile. 


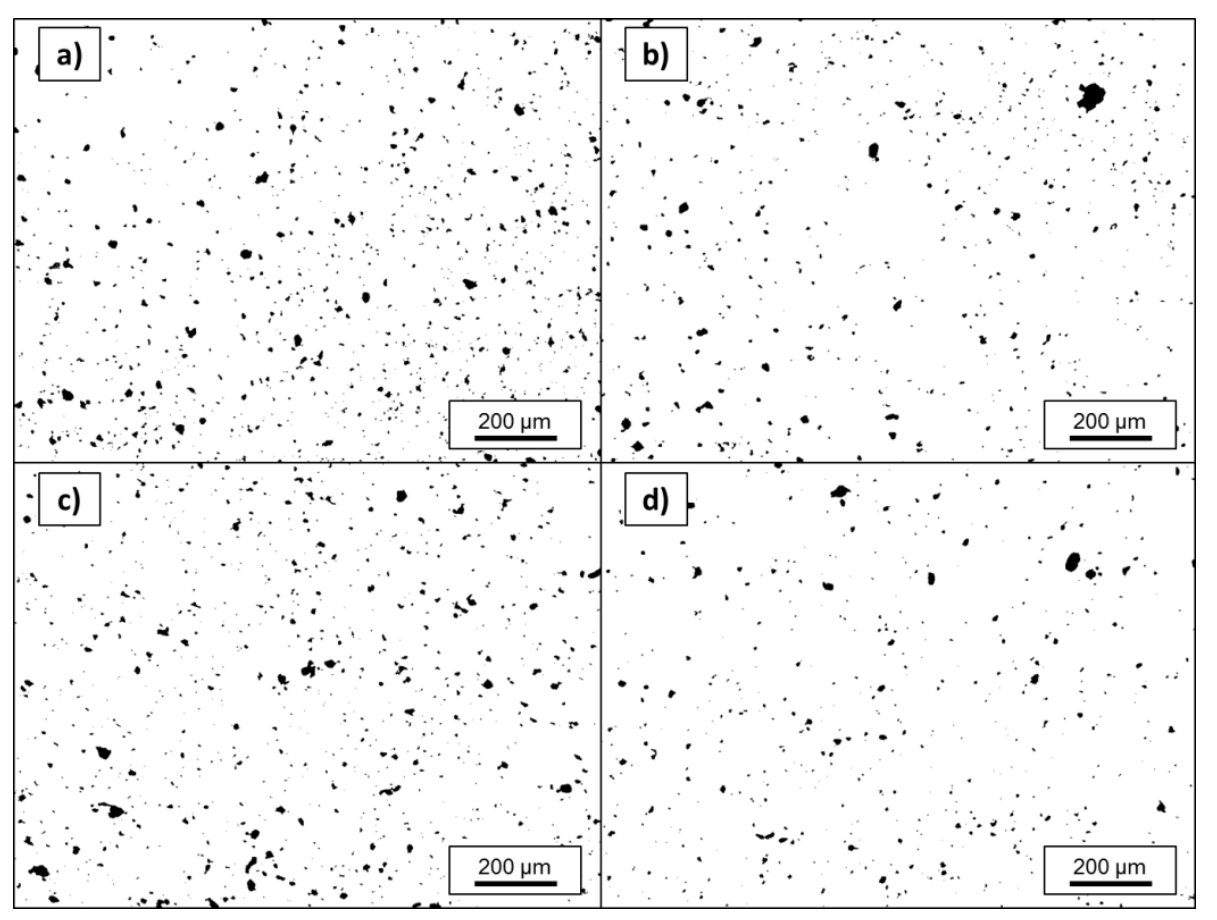

Figure 2: Light-transmission microscopy of polypropylene nanocomposites: a) 0.5T/1.0P Low temperature profile, b) 1.0T/0.5P Low temperature profile, c) 0.5T/1.0P High temperature profile, d) 1.0T/0.5P High temperature profile.

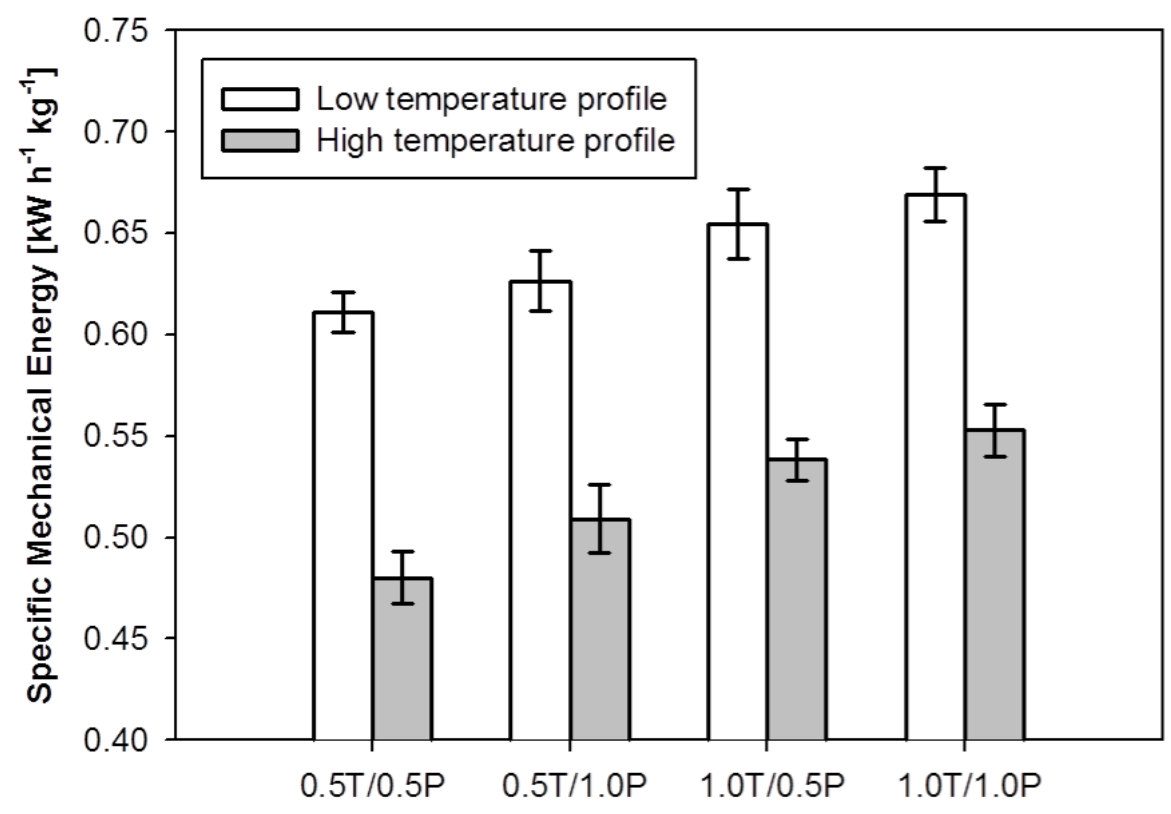

Figure 3: Specific mechanical energy of polypropylene nanocomposites at different processing conditions. 


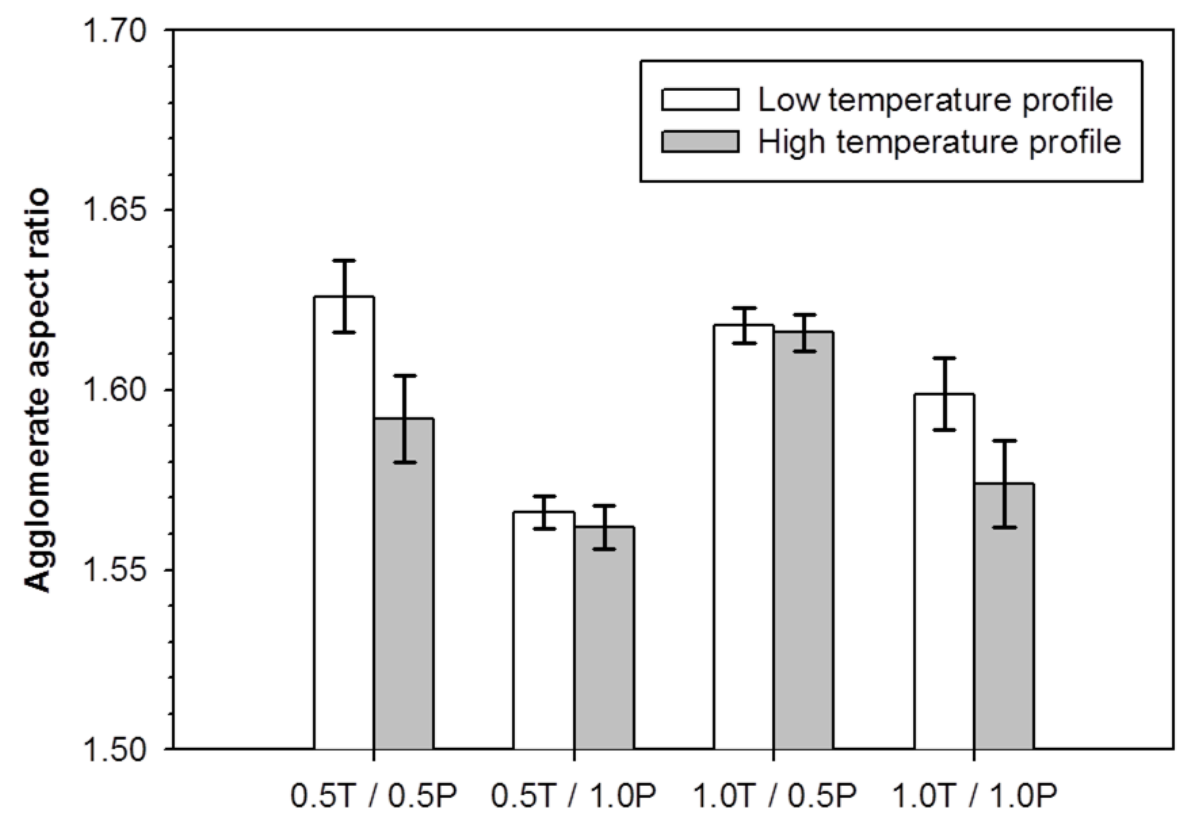

Figure 4: Agglomerate aspect ratio in polypropylene nanocomposites extruded at various temperature profiles.

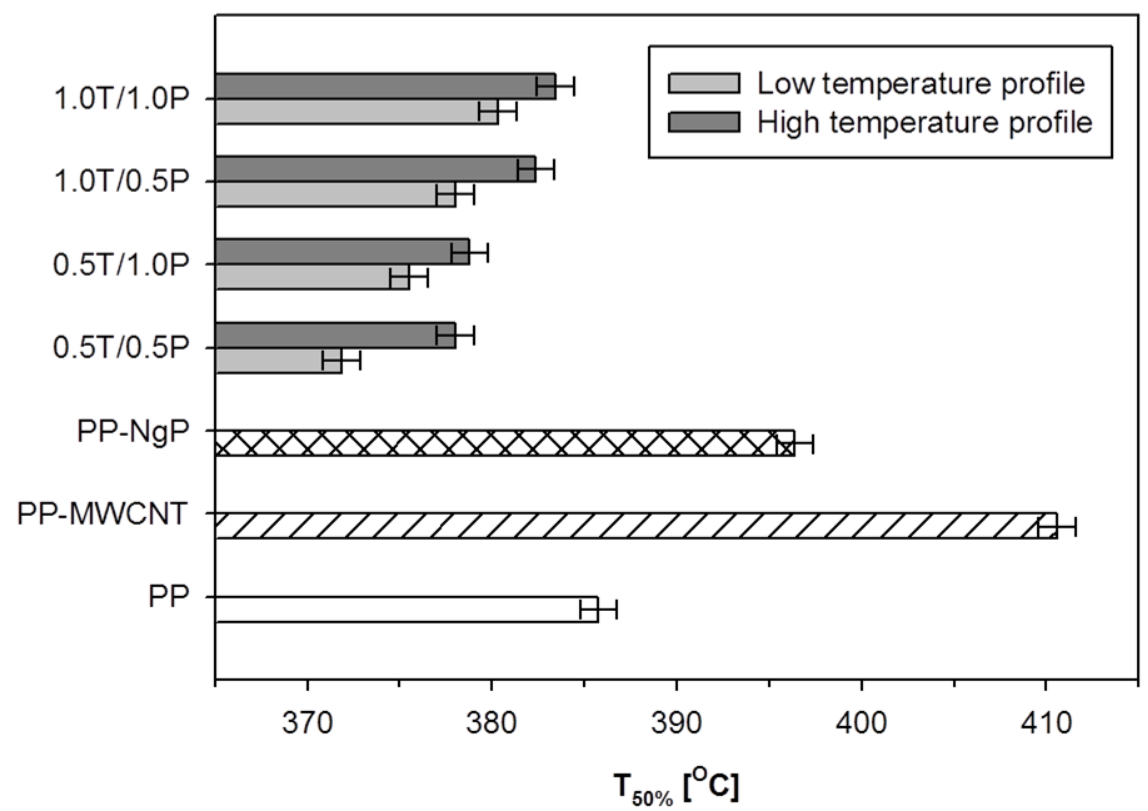

Figure 5: Temperature of 50\% weight loss of polypropylene nanocomposites extruded at various temperature profiles. 

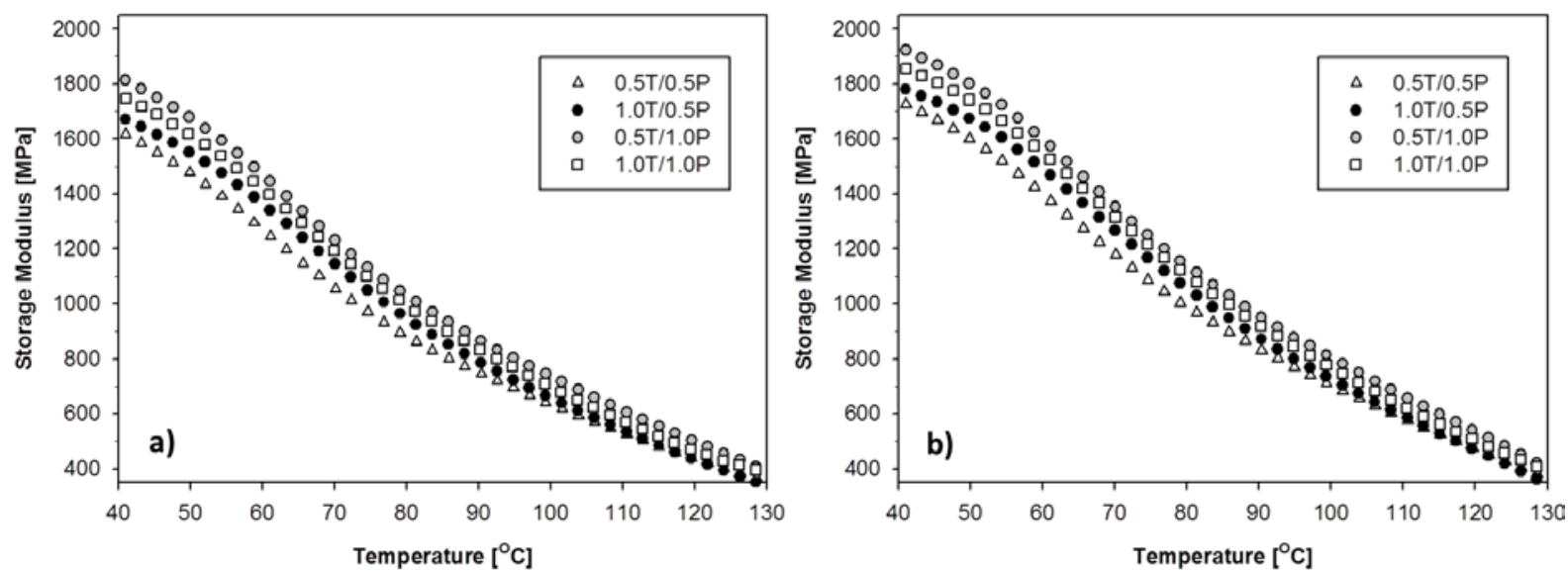

Figure 6: Storage modulus of PP/MWCNT/GnP nanocomposites extruded at various temperature profiles: a) low-temperature profile, b) high-temperature profile. 